\title{
Nonfatal Occupational Falls Among U.S. Health Care Workers, 2008-2010
}

\author{
Han T. Yeoh, PhD [Research Scientist], Thurmon E. Lockhart, PhD [Associate Professor], \\ and Xuefang Wu, MSc [Doctoral candidate] \\ Grado Department of Industrial and Systems Engineering, Virginia Polytechnic Institute and State \\ University, Blacksburg, VA
}

Han T. Yeoh: han1@vt.edu

\begin{abstract}
The purpose of this study was to describe antecedents and characteristics of nonfatal fall-related injuries among health care workers in the United States. A special request was made for the Bureau of Labor Statistics to obtain nonfatal fall-related injury data from 2008 to 2010. Overall, workers in the nursing-related profession had the highest percentages of workplace fall-related injuries. Ninety-one percent of these injured workers were female, and more than $50 \%$ were between the ages of 45 and 64 years. More than $25 \%$ of fall injuries resulted in 31 or more workdays being lost. This study indicated that the most affected body parts were the lower extremities, with most injuries resulting in sprains, strains, and tears. Accordingly, this 3-year study revealed that a high number of fall injuries occurred at night for health care workers compared to other workers in the U.S. private sector.
\end{abstract}

Fall accidents are prevalent in the workplace and are responsible for a significant proportion of worker absenteeism and disability (Yeoh, Lockhart, \& Wu, 2012; Yoon \& Lockhart, 2006). Injuries from a fall contribute, on average, a greater number of days away from work than other occupational injuries and illnesses (Yoon \& Lockhart, 2006). According to Cotnam, Chang, and Courtney (2000), the health care industry is the largest employer group in the United States (i.e., 13 million employees), and ranks second among eight industries with the highest percentage of claim costs associated with falls. The lost workday injury rate due to falls on the same level in nursing homes and residential care facilities was 38.2 per 10,000 employees, $90 \%$ greater than the average fall rate for all other private industries combined (i.e., 20.1 per 10,000 employees) (Bureau of Labor Statistics, 2009). Employment demand for nurses is expected to create a $20 \%$ shortage in the nursing labor pool by 2015 and $30 \%$ by 2020 (American Nurses Association, 2003). The high injury rate, coupled with a critical nursing shortage, raises serious concerns about the nursing work force's capacity to care for the nation's growing population. This critical shortage will place additional pressure on the nursing labor pool, increasing the workload and possibly increasing occupational injuries. In addition to risking their own health and safety, fall incidents among nurses can frequently result in serious disabling injuries that impact their ability to complete job tasks, including diminished ability to care for patients (U.S. Department of Health and Human Services, 2010). The aim of this study was to address the chain of events in a nonfatal fallrelated accident: the exposure to hazards, the initiating events, and the final outcome leading to injury and disability.

Copyright (C) American Association of Occupational Health Nurses, Inc.

The authors have disclosed no potential conflicts of interest, financial or otherwise. 


\section{METHODS}

The Bureau of Labor Statistics compiles national data on nonfatal occupational injuries and illnesses in private industry from the Survey of Occupational Injuries and Illnesses (SOII) and estimates the overall occupational injury and illness experience (Bureau of Labor Statistics, 2011). Nonfatal injury and illness-related work absences of 1 or more days are classified by nature, source, injured body part, age, gender, occupation, race, and length of service. To better understand the risks of injuries from a fall for this work group, a special request was made for the Bureau of Labor Statistics to release nonfatal fall-related injury data on health care workers. Health care workers in this study were from two major occupational groups classified by the Bureau of Labor Statistics: "29-0000 Healthcare Practitioners and Technical Occupations" and "31-0000 Healthcare Support Occupations" (Bureau of Labor Statistics, 2010). Healthcare Practitioners and Technical Occupations includes chiropractors, dentists, dietitians and nutritionists, optometrists, pharmacists, anesthesiologists, family and general practitioners, obstetricians and gynecologists, pediatricians, psychiatrists, podiatrists, registered nurses, therapists, veterinarians, audiologists, health diagnosing and treating practitioners, medical and clinical laboratory technicians, dental hygienists, radiologic technologists and technicians, emergency medical technicians and paramedics, licensed practical and licensed vocational nurses, medical records and health information technicians, opticians, dispensing, orthotists and prosthetists, health technologists and technicians, occupational health and safety specialists, occupational health and safety technicians, athletic trainers, health care practitioners, and technical workers. Conversely, Healthcare Support Occupations includes home health aides, nursing assistants, orderlies, occupational therapy assistants and aides, physical therapy assistants and aides, massage therapists, dental assistants, medical assistants, medical equipment preparers, medical transcriptionists, pharmacy aides, veterinary assistants and laboratory animal caretakers, and phlebotomists. Identifying the nature, affected body part, occupation, age group, gender, days away from work, time of fall, and event distribution of injuries provides a detailed overview of the risk of falls among these workers. The current study is a compendium of fall-related injury data based on the SOII, from 2008 to 2010. All nonfatal injury and illness data in this article involved at least 1 day away from work following the day the incident occurred. The data published in this article have been certified by the Bureau of Labor Statistics to maintain accuracy (Andrew Kato, Economist, Injuries, Illnesses, and Fatalities Program, Office of Safety and Health Statistics, Bureau of Labor Statistics, personal communication, September 21, 2012).

\section{RESULTS}

Table 1 specifies the 3-year period from 2008 to 2010 in which approximately 2.98 million work-related nonfatal injuries involving days away from work occurred in the United States; more than $22.1 \%(656,070)$ of these accompanied falls. Of the 656,070 fall injuries, 73,030 cases (11.2\%) were reported by health care workers. The Bureau of Labor Statistics categorizes four main events or exposures in fall-related injuries: "fall to lower level," "fall on same level," "jump to lower level," and "unspecified" events. Fall on same level events occur when contact with the source of injury is made on the same level or above the surface supporting the injured person. Fall to lower level events occur when the source of injury makes contact below the surface level supporting the individual. Conversely, jump to lower level events transpire when the injured person voluntarily leaps from an elevation, albeit to avoid an uncontrolled fall or other injury. Events peripheral to these categories are labeled unspecified. The percentage of fall-related injuries for each event is shown in Table 2. Among these events, fall on same level cases were associated with the most fall-related injuries, with $84.5 \%$ of total occupational falls occurring this way, followed by fall to lower level cases, accounting for $12.8 \%$ of all injuries. 
Table 3 presents the total number and percentage of fall injuries by gender and age group. The results indicate that the majority of the victims were female workers: $91.9 \%$ women compared to only $8.0 \%$ men during the 3 years. Among the age groups, the 45 to 54 year olds had the highest number of injuries $(28.4 \%)$; the 55 to 64 year olds and the 35 to 44 year olds were the second and third largest fall populations, with $22.5 \%$ and $20.2 \%$, respectively. The percentage of fall-related injuries among selected occupations is also listed in Table 3. Workers in the nursing aides-orderlies-and attendants occupation had the highest number of fall-related injuries involving days away from work-34.4\% of total falls.

The characteristics of occupational falls are presented in Table 4: part of body injured, nature of the injury, number of days away from work, and time of day injury occurred. The lower extremities - knees, feet, and toes-were the most affected areas, accounting for an average of $26.2 \%$ of total fall-related injuries. Workers injured multiple body parts in approximately $26.2 \%$ of fall-related accidents; the Bureau of Labor Statistics uses the classification multiple body parts for any injury in which body parts from two or more divisions of the body are injured. The trunk, including the shoulders and the back, was the third most injured body part $(22.1 \%)$. Regarding the nature of the injury, sprain-strain-tear (40\%), bruise-contusion (15.7\%), and fracture (11.5\%) contributed to more than $65 \%$ of the fall-related injuries during the past 3 years. In terms of absence from work, more than $25 \%$ of health care workers' falls resulted in 31 or more workdays lost, followed by $19.4 \%$ for 3 to 5 days away from work. Table 4 reveals that falls reported between 8:01 a.m. and 4:00 p.m. and 4:01 p.m. and 12:00 a.m. contributed to $25.7 \%$ and $19.9 \%$ of all falls, respectively. Moreover, falls that occurred between 4:01 a.m. and 8:00 a.m. contributed to approximately $15.5 \%$ of the total fall-related injuries.

\section{DISCUSSION}

The current study provides a detailed analysis of nonfatal fall-related injuries among health care workers in U.S. private industry from 2008 to 2010. Although the number of overall occupational injuries involving days away from work decreased by 144,940 during the 3year period (i.e., 1,078,140 cases in 2008 to 933,200 cases in 2010), the percentage of overall fall injuries actually increased incrementally, from $21.8 \%$ in 2008 to $22.3 \%$ in 2010 (Table 1). The results suggest that fall injuries among health care workers contribute to more than $11 \%$ of overall occupational injuries. The Bureau of Labor Statistics (2009) reported that the lost workday injury rate due to falls on same level in nursing homes and residential care facilities was 38.2 per 10,000 employees, which was $90 \%$ greater than the average rate for all other private industries combined (20.1 per 10,000 employees). The current study results indicate that $84.5 \%$ of the fall injuries were falls on the same level.

Female workers were involved in a considerably greater proportion of injuries associated with falls than male workers (average of $91.9 \%$ vs. $8.0 \%$ during the 3 -year period), because women hold the majority of jobs in the health care sector. Accordingly, falls are a significant problem for the aging work force. The combination of the 45 to 54 years and 55 to 64 years age groups' injury histories yielded the total injury rate of 50.9 per 100 associated with falls. Kemmlert and Lundholm (2001) reported that older workers were more likely to suffer from slips, trips, and fall-related injuries. Fall-related accidents among the elderly may be associated with age-related deterioration in visual, proprioceptive, and vestibular signals concerning postural control (Lockhart, Woldstad, \& Smith, 2003; Lockhart, Woldstad, Smith, \& Ramsey, 2002). Nursing aides-orderlies-and attendants was the major occupational group that had the highest number of falls, 34.4\% during the past 3 years, followed by registered nurses and miscellaneous healthcare support occupations, with $19.6 \%$ and $12.6 \%$, respectively. Licensed practical and licensed vocational nurses ranked fourth, with $8.2 \%$ during the preceding 3 years. Nursing aides-orderlies-and attendants are workers 
who provide basic patient care under the direction of the nursing staff and perform duties such as feeding, bathing, dressing, grooming, or moving patients, or changing linens. Miscellaneous healthcare support occupations includes dental assistants, medical assistants, medical equipment preparers, medical transcriptionists, pharmacy aides, veterinary assistants and laboratory animal caretakers, and phlebotomists. Current findings demonstrate that falls are a growing concern for workers in nursing-related occupations; registered nurses, licensed practical and licensed vocational nurses, and nursing aides-orderlies-and attendants occupational groups reported $62.2 \%$ of all fall injuries.

Although the falls reported in this study involved nonfatal injuries, they can still be severe (i.e., skeletal fractures, muscle strains, back injuries, and concussions) (Cattledge, Schneiderman, Stanevitch, Hendricks, \& Greenwood, 1996; Courtney, Matz, \& Webster, 2002). Injuries due to falls are a major cause of years lived with disability (Murray \& Lopez, 1996). The results of this analysis indicated that the most affected body parts were the lower extremities and the trunk. The correlation between aging and skeletal fractures, particularly female worker fall on the same level injuries, cannot be overstated as several studies have reported that women 45 years and older are at increased risk of fracture due to falls (Cherry et al., 2005; McNamee, Kemmlert, Lundholm, \& Cherry, 1997; Stevens \& Sogolow, 2005). One fourth of the health care workers who suffered from falls required 31 or more days to recover, which may impact health care employees' ability to return to work and care for patients (U.S. Department of Health and Human Services, 2010).

Because more employees work from 8:01 a.m. to 4:00 p.m., the total number of falls that occurred during this time period generated more than $45 \%$ of the total injuries. Interestingly, this 3-year study revealed that a high number of occupational fall injuries occurred during the 12:01 a.m. to 8:00 a.m. time period (20.1\%), compared to the national average of $14.6 \%$. Despite its links with decreased sleep quantity and quality (Charles et al., 2007), metabolic syndrome (Esquirol et al., 2009; Violanti et al., 2009), metabolic risk factors for cardiovascular disease (Ha \& Park, 2005), and prostate cancer (Kubo et al., 2006), night shift work is common in the health care industry. Further, Flain (1986) reported that $36 \%$ of health care workers engage in shift work; among them, nursing staff were the largest group of professionals on the health care team, providing 24-hour patient care across a 7-day work week. Horwitz and McCall (2004) found that night shift health care workers had an increased risk of injury (risk ratio $=1.58$ ) compared to daytime workers. Although the National Institute for Occupational Safety and Health (NIOSH) has released a workbook on slips, trips, and falls causes in an attempt to offer prevention advice to health care workers (U.S. Department of Health and Human Services, 2010), more fall prevention research is needed for night shift workers to prevent falls.

Several limitations are noted. The Bureau of Labor Statistics data were subject to employees' recollections of the incidents and their ability to identify environmental risk factors. Furthermore, the narrative analysis method is limited by the completeness and consistency of the available text data (Lincoln et al., 2004). For instance, Lombardi et al. (2005) reported that it is not known whether words were truncated, forgotten, omitted, or even lost in conversation by those reporting or recording the claim. In fact, growing evidence suggests that the annual Bureau of Labor Statistics SOII underestimates the true injury burden due to the under-reporting of injuries (Azaroff, Levenstein, \& Wegman, 2002; Boden \& Ozonoff, 2008).

\section{IMPLICATIONS FOR PRACTICE}

Employment demand for nurses is expected to create a shortage in the nursing labor pool of $20 \%$ by 2015 and $30 \%$ by 2020 . The high injury rate, coupled with a critical nursing 
shortage, raises serious concerns about the nursing work force's capacity to care for the nation's growing population. This critical shortage will place additional pressure on the nursing labor pool, increasing both the workload and the possibility of occupational injuries. The purpose of this study was to describe the characteristics and antecedents of occupational fall injuries among health care workers. This information can be used by occupational health and safety professionals to design and implement preventive measures in the U.S. health care industry and to provide workers with an understanding of risk factors associated with falls in the workplace. Considering the direct and indirect costs (e.g., lost productivity and stress for workers' families), occupational falls bring enormous burdens to society. As Leamon and Murphy (1995) concluded, "Based on the frequency and costs to industry and workers, prevention of falls should be given a high priority" (p. 495). Preventive actions by the employer should be multidimensional, including a review of organizational practices and policies, work environment, and health management programming.

\section{Acknowledgments}

This research was supported by funding from the National Science Foundation (Grant \#CBET-0756058), the National Institute for Occupational Safety and Health (Grant \#CDC/NIOSH-R01-OH009222), and the National Institutes of Health (L30-AG022963-04/NIH HHS/United States) to Dr. Lockhart.

The authors acknowledge the help and cooperation of the Bureau of Labor Statistics, without which this study could not have been done. They also thank Andrew Kato of the Bureau of Labor Statistics for his help in preparing the data.

\section{References}

American Nurses Association. Ergonomics/handle with care. 2003. Retrieved from www.nursingworld.org/MainMenuCategories/OccupationalandEnvironmental/occupationalhealth/ handlewithcare.aspx

Azaroff LS, Levenstein C, Wegman DH. Occupational injury and illness surveillance: Conceptual filters explain underreporting. American Journal of Public Health. 2002; 92:1421-1429. [PubMed: 12197968]

Boden LI, Ozonoff A. Capture-recapture estimates of nonfatal workplace injuries and illnesses. Annals of Epidemiology. 2008; 18:500-506. [PubMed: 18083542]

Bureau of Labor Statistics. Incidence rates for nonfatal occupational injuries and illnesses involving days away from work per 10,000 full-time workers by industry and selected events or exposures leading to injury or illness, 2008. 2009. Retrieved from www.bls.gov/iif/oshcdnew.htm

Bureau of Labor Statistics. The 2010 Standard Occupational Classification System. 2010. Retrieved from www.bls.gov/soc/classification.htm

Bureau of Labor Statistics. Case and demographic characteristics for work-related injuries and illnesses involving days away from work 2006-2010. 2011. Retrieved from www.bls.gov/iif/ oshcdnew.htm

Cattledge G, Schneiderman A, Stanevitch R, Hendricks S, Greenwood J. Nonfatal occupational fall injuries in the West Virginia construction industry. Accident; Analysis and Prevention. 1996; 28:655-663.

Charles LE, Burchfiel CM, Fekedulegn D, Vila B, Hartley TA, Slaven J, et al. Shift work and sleep: The Buffalo Police Health Study. Policing: An International Journal of Police Strategies \& Management. 2007; 30(2):215-227.

Cherry N, Parker G, McNamee R, Wall S, Chen Y, Robinson J. Falls and fractures in women at work. Occupational Medicine. 2005; 55:292-297. [PubMed: 15982978]

Cotnam JP, Chang WR, Courtney TK. A retrospective study of occupational slips, trips, and falls across industries. Human Factors and Ergonomics Society. 2000; 4:473-476.

Courtney TK, Matz S, Webster BS. Disabling occupational injury in the US construction industry, 1996. Journal of Occupational and Environmental Medicine. 2002; 44(12):1161-1168. [PubMed: 12500458] 
Esquirol Y, Bongard V, Mabile L, Jonnier B, Soulat JM, Perret B. Shift work and metabolic syndrome: Respective impacts of job strain, physical activity, and dietary rhythms. Chronobiology International. 2009; 26:544-559. [PubMed: 19360495]

Flain PO. Work schedules of Americans: An overview of new findings. Monthly Labor Review. 1986; 109:3-6.

Ha M, Park J. Shiftwork and metabolic risk factors of cardiovascular disease. Journal of Occupational Health. 2005; 47:89-95. [PubMed: 15824472]

Horwitz IB, McCall B. The impact of shift work on the risk and severity of injuries for hospital employees: An analysis using Oregon workers' compensation data. Occupational Medicine. 2004; 54:556-563. [PubMed: 15385648]

Kemmlert K, Lundholm L. Slips, trips and falls in different work groups with reference to age and from a preventive perspective. Applied Ergonomics. 2001; 32:149-153. [PubMed: 11277507]

Kubo T, Ozasa K, Mikami K, Wakai K, Fujino Y, Watanabe Y, et al. Prospective cohort study of the risk of prostate cancer among rotating-shift workers: Findings from the Japan collaborative cohort study. American Journal of Epidemiology. 2006; 164:549-555. [PubMed: 16829554]

Leamon TB, Murphy PL. Occupational slips and falls: More than a trivial problem. Ergonomics. 1995; 38:487-498. [PubMed: 7729391]

Lincoln AE, Sorock GS, Courtney TK, Wellman HM, Smith GS, Amoroso PJ. Using narrative text and coded data to develop hazard scenarios for occupational injury interventions. Injury Prevention. 2004; 10:249-254. [PubMed: 15314055]

Lockhart TE, Woldstad JC, Smith JL. Effects of age-related gait changes on biomechanics of slips and falls. Ergonomics. 2003; 46(12):1136-1160. [PubMed: 12933077]

Lockhart TE, Woldstad JC, Smith JL, Ramsey JD. Effects of age related sensory degradation on perception of floor slipperiness and associated slip parameters. Safety Science. 2002; 40:689-703. [PubMed: 20607132]

Lombardi DA, Pannala R, Sorock GS, Wellman H, Courtney TK, Verma S, et al. Welding related occupational eye injuries: A narrative analysis. Injury Prevention. 2005; 11:174-179. [PubMed: 15933411]

McNamee R, Kemmlert K, Lundholm L, Cherry NM. Injuries after falls at work in the United Kingdom and Sweden with special reference to fractures in women over 45. Occupational and Environmental Medicine. 1997; 54:785-792. [PubMed: 9538350]

Murray, CJL.; Lopez, AD. The global burden of disease. Boston, MA: Harvard University Press; 1996. Global and regional descriptive epidemiology of disability: Incidence, prevalence, health, expectancies, and years lived with disability.

Stevens JA, Sogolow ED. Gender differences for non-fatal unintentional fall related injuries among older adults. Injury Prevention. 2005; 11:115-119. [PubMed: 15805442]

U.S. Department of Health and Human Services. Slip, trip, and fall prevention for healthcare workers. 2010 Dec. (Publication no. 2011-123). Retrieved from www.cdc.gov/niosh/docs/2011-123/pdfs/ 2011-123.pdf

Violanti JM, Burchfiel CM, Hartley TA, Mnatsakanova A, Fekedulegn D, Andrew ME, et al. Atypical work hours and metabolic syndrome among police officers. Archives of Environmental and Occupational Health. 2009; 64:194-201. [PubMed: 19864222]

Yeoh HT, Lockhart TE, Wu X. Nonfatal occupational falls on the same level. Ergonomics. 201210.1080/0014013.2012.746739

Yoon HY, Lockhart TE. Nonfatal occupational injuries associated with slips and falls in the US. International Journal of Industrial Ergonomics. 2006; 36:83-92. [PubMed: 20607131] 


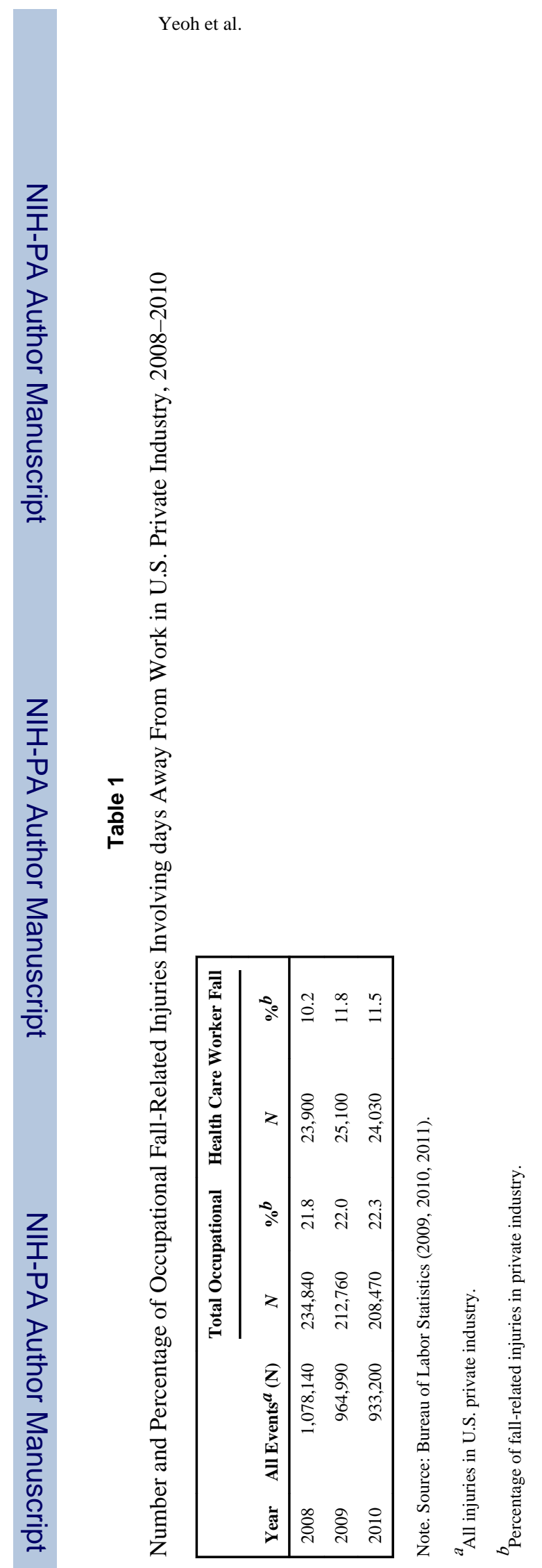

Workplace Health Saf. Author manuscript; available in PMC 2013 July 27. 


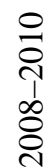

章

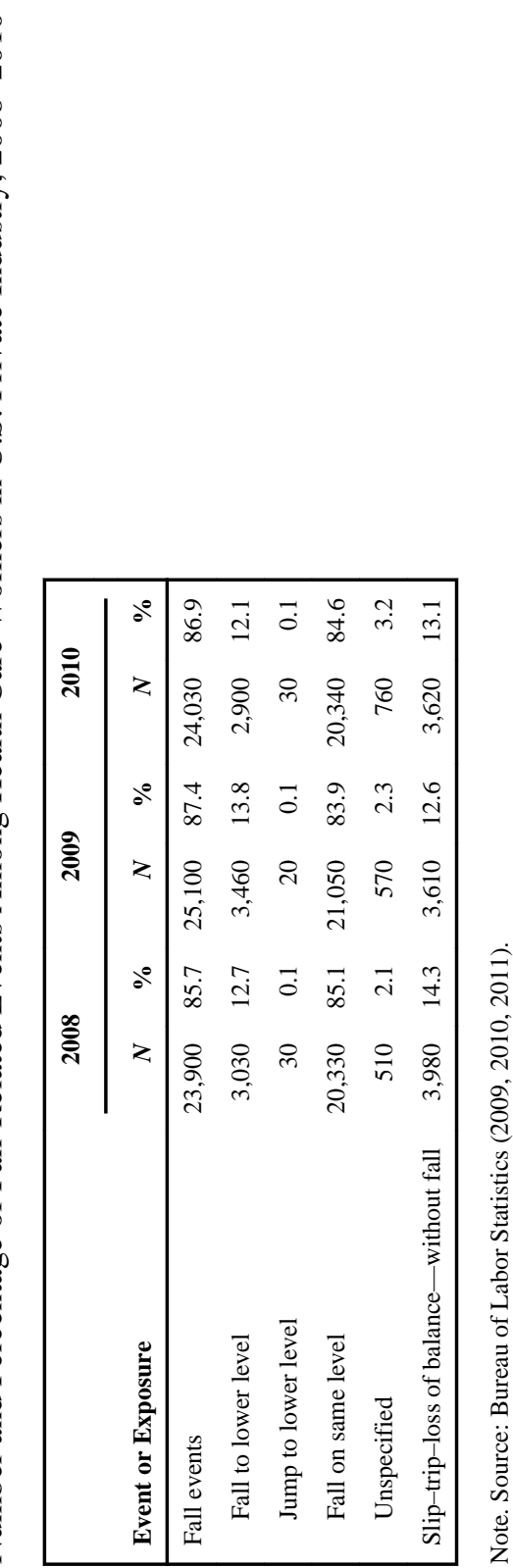

Workplace Health Saf. Author manuscript; available in PMC 2013 July 27. 


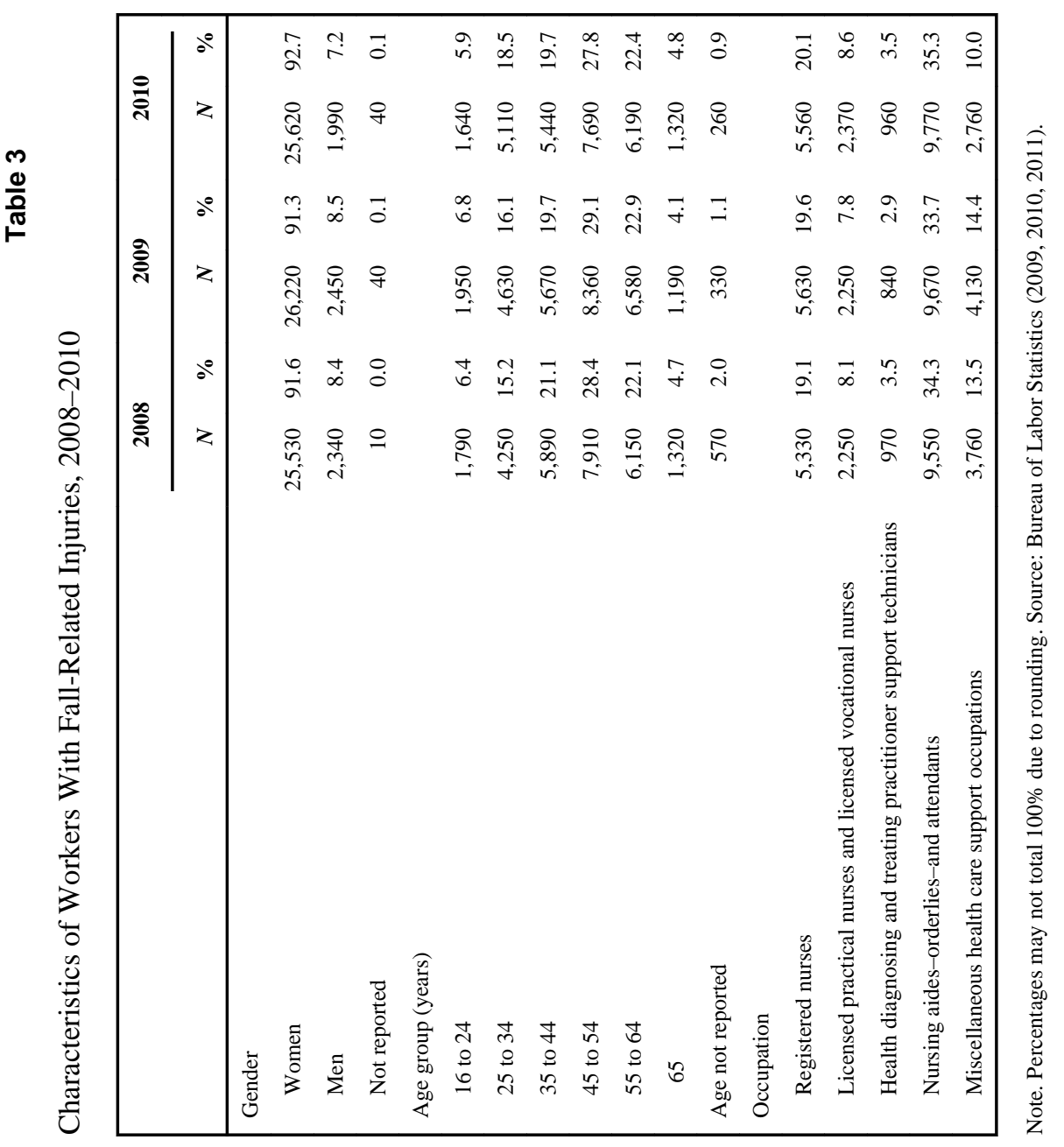

Workplace Health Saf. Author manuscript; available in PMC 2013 July 27. 


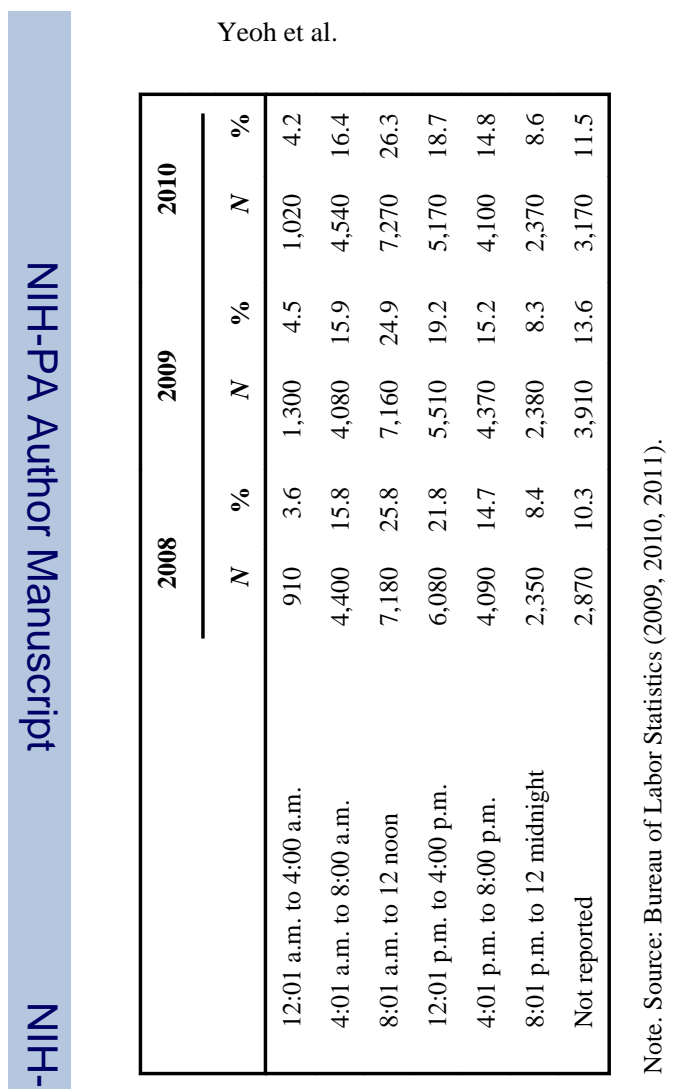

Page 11 